\title{
ACIDITY AND DC CONDUCTIVITY IN POLAR ICE
}

\section{(Abstract)}

\author{
by
}

E.W. Wolff and J.G. Paren

(British Antarctic Survey, Natural Environment Research Council, High Cross, Madingley Road, Cambridge CB3 OET, England)

It has previously been suggested (Maccagnan 1981) that the dc conductivity of the ice of polar ice sheets could be due to the presence of liquid layers at grain boundaries. These layers would consist of acids at concentrations determined by conventional phase diagrams of acid/water/ice mixtures; the size of the layers for a given temperature would be determined by the bulk concentration of impurities. Thermodynamic arguments suggest that it is plausible that the liquid will be localized at the junction of three grains in preference to wetting all grain boundary surfaces. With these assumptions we have formulated a model (Wolff and Paren 1984) from which the conductivity (and its temperature dependence) may be calculated for any impurity concentration. Using acid concentrations typical of the ice of polar regions we derive similar conductivities to those found in deep impermeable polar ice using field and laboratory methods of conductivity measurement. Polar ice has only a narrow range of conductivity and is in agreement with the model since we find a correspondingly small range in acidity between ice samples from maritime and continental sites in both polar regions. Previous theories based on incorporating impurities into the ice lattice, leading to a change of ionic balance, fail to predict the observed conductivities from a knowledge of the acidity. If the model is proven, it would have important implications for the interpretation of conduction phenomena such as the layering observed in radio echo sounding.

\section{REFERENCES}

Maccagnan M 1981 Contribution à l'étude des propriétés diélectriques de la glace antarctique; application géochimique. Laboratoire de Glaciologie et Géophysique de l'Environnement du CNRS. Publication 373

Wolff E W, Paren J G 1984 A two-phase model of electrical conduction in polar ice sheets. Journal of Geophysical Research 89(B11): 9433-9438 